\title{
Human Papillomavirus Infection in Child
}

\author{
G. Fabbrocini*, S. Cacciapuoti and G. Monfrecola
}

Department of Systematic Pathology, Section of Dermatology, University of Naples Federico II, Naples, Italy

\begin{abstract}
Human papilloma viruses (HPV) have been identified as the cause of cutaneous and genital warts. Furthermore, HPV DNA can also be detected in certain malignant epithelial tumors such as cervical carcinoma and cutaneous squamous cell cancer. HPV infections in children, particularly when occurring as condylomata acuminata, present a difficult and often puzzling problem. The modes of viral transmission in child remain controversial, including perinatal transmission, auto- and hetero-inoculation, sexual abuse, and, possibly, indirect transmission via fomites. The treatment of warts and condylomata acuminate in child poses a therapeutic challenge for physicians. No single therapy has been proven effective at achieving complete remission in every patient. As a result, many different approaches to therapy exist. The proper approach to the management of warts depends on the age of the patient, location, size, extent, and type of wart, and duration of lesions. Each treatment decision should be made on a case-by-case basis according to the experience of the physician, patient preference, and the application of evidence-based medicine. In order to modify HPV epidemiology, HPV prophylactic vaccine has been recently proposed for children. The purpose of this review is to update the reader with the latest information on the HPV and its therapeutics in children.
\end{abstract}

Keywords: HPV, child, perinatal transmission, sexual abuse.

\section{INTRODUCTION}

Human papillomaviruses (HPV) are double-stranded DNA viruses that can induce hyperplastic, papillomatous and verrucous squamous cell lesions in the skin and at various mucosal sites. HPV has more than 100 distinct genotypes, of which approximately 40 can infect the genital tract. HPV genotypes designated as high risk are associated with anogenital cancers, and low-risk genotypes are associated with the development of dysplasia and anogenital warts. HPV-16 and HPV-18 are associated with $70 \%$ of squamous cell carcinomas and $86 \%$ of adenocarcinomas of the cervix. These same genotypes are also implicated in cancers of the penis, anus, vulva and vagina, as well as in squamous cell cancers of the conjunctiva, mouth, oropharynx, tonsils and larynx. Six HPV genotypes (HPV-31, -33, -35, -45, -52 and 58) are responsible for an additional $20 \%$ of cervical cancers worldwide [1]. HPV can be classified into mucosal and cutaneous types. Mucosal types infect the mucous membranes and can cause cervical neoplasia in adults as well as anogenital warts in both children and adults. Cutaneous types infect the squamous epithelium of the skin and produce common warts, plantar warts, and flat warts, which occur commonly on the hands, face, and feet. Specific cutaneous types are also detected in epidermodysplasia verruciformis, a rare familial disorder that is related to the development of large cutaneous warts that can progress to skin cancer and WHIM syndrome, a rare combined immunodeficiency syndrome which is characterized by warts, hypogammaglobulinemia, recurrent bacterial infections, and myelokathexis [2]. HPV have been difficult to study in part

*Address correspondence to this author at the Department of Systematic Pathology, Section of Dermatology, University of Naples Federico II, 80133 Naples, Italy; Tel: 00393335404428; Fax: 0039335404467;

E-mail: gafabbro@unina.it because they have not yet been propagated in tissue culture. Fortunately, advances in molecular biology have allowed characterization of HPV genomes and identification of some HPV gene functions. HPV infections are not only common but also difficult to treat and prevent. There is often a long latent period and subclinical infections, and HPV DNA can be found in normal tissue adjacent to lesions. While genital HPV infections seem to affect predominantly adult, sexually active age groups, skin warts at various anatomic sites have been characteristically regarded as a disease affecting children. Apart from these cutaneous HPV lesions, HPV infections of the oral mucosa, and particularly those of the larynx, seem to be typical pediatric diseases as well.

\section{HPV MODALITY OF TRASMISSION}

The modes of viral transmission in children remain important and controversial. Several potential modes of transmission can be theorized for pediatric HPV infections, including perinatal transmission, auto- and heteroinoculation, sexual abuse, and, possibly, indirect transmission via fomites (Table 1).

Infections with HPV types causing skin warts are usually acquired through micro-injuries. Transmission occurs either directly from one person to another, or indirectly via contaminated objects or surfaces. Auto-inoculation (by scratching) from one site of the body to another is also possible. HPV 2 is frequently detected in lesions of the oral mucosa, and it might be acquired by the chewing of common warts present on hands. HPV is described as the most common sexually transmitted infection, but in contrast to the unequivocal data on sexual transmission of genital warts in adults and sexually active adolescents, reports on the primary mode of transmission of genital warts in children have been more contradictory [3]. HPV DNA has been found in cervices of up to $35 \%$ of adolescent women, a minority of 


\section{Table 1. Modes of HPV Transmission in Children}

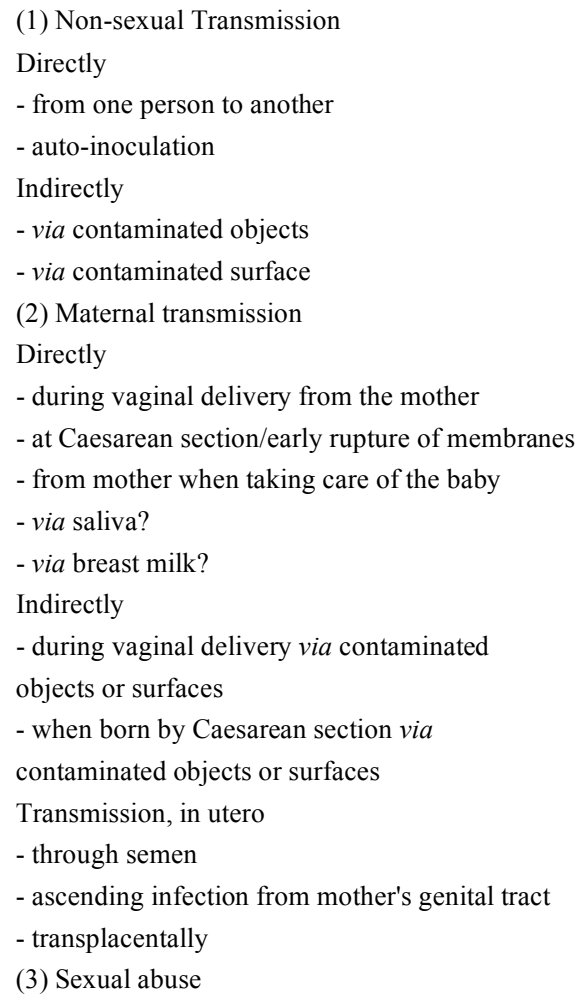

these women have clinically apparent warts $[4,5]$ Condylomata have been reported in $1-2 \%$ of abused children and $50 \%$ to $75 \%$ of cases of genital warts in children reported in the literature appear to be the result of abuse [6].

\section{CLINICAL MANIFESTATION OF HPV INFECTION IN CHILDREN}

\section{Cutaneous Warts}

Cutaneous viral warts are discrete benign epithelial proliferations caused by the HPV. Common, plantar, or flat warts are cutaneous manifestations of the human papillomavirus. Warts may exist in different forms given the epithelial surface and HPV type responsible for the infection. Common warts (Fig. 1) (Verruca vulgaris), plantar warts (Verruca plantaris), flat or planar warts (Verruca plana) (Fig. 2) are some of the clinical manifestations of HPV infection (Table 2) [7].

Cutaneous warts prevalence increases during childhood, peaks in adolescence, and declines thereafter [8]. In healthy children, warts resolve spontaneously; $93 \%$ of children with warts at age 11 showed resolution by age 16 [9]. A study [10] examining the natural progression of warts indicated that warts will spontaneously clear after two years without treatment in 40 percent of children. Resolution can be preceded by the appearance of blackened thrombosed capillary loops. Warts typically continue to increase in size and distribution and may become more resistant to treatment over time [11]. Children with treatment-resistant warts potentially may be reservoirs for HPV transmission. In addition, warts can be painful depending on their location (e.g. soles of the feet and near the nails) and viewed as socially unacceptable when located on visible areas (e.g. hands and face) [12]. Moreover, warts may be widespread and persistent in patients who are immunocompromised.

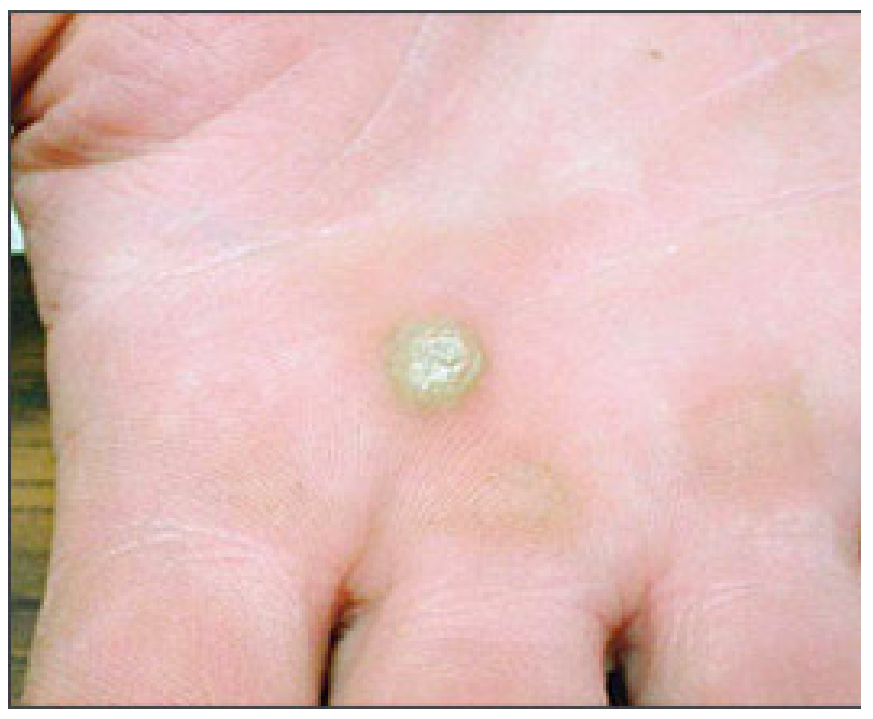

Fig. (1). Verruca vulgaris: hyperkeratotic surface of grossly thickened keratin.

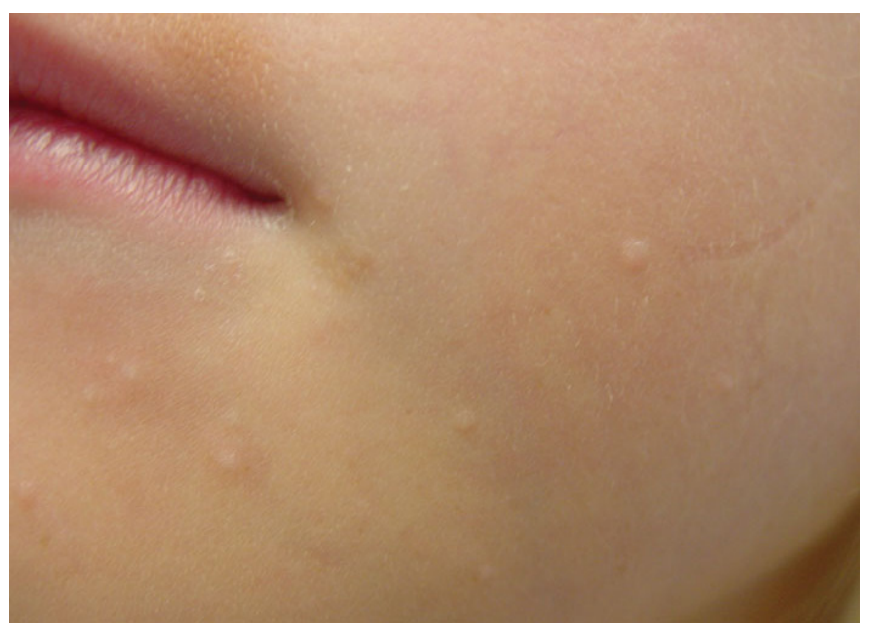

Fig. (2). Verruca plana or flat wart: flat warts may be confused with comedones.

The treatment of warts poses a therapeutic challenge for physicians. No single therapy has been proven effective at achieving complete remission in every patient. As a result, many different approaches to wart therapy exist. Each treatment decision should be made on a case-by-case basis according to the experience of the physician, patient preference, and the application of evidence-based medicine. Although most warts resolve spontaneously within two years, some persist and become large and painful. Immunocompromised patients with warts may exhibit incomplete clearance, and the warts may be resistant to treatment [13]. For this reason many parents present their children for medical treatment. Treatment of cutaneous warts in children should be simple, cheap, effective, safe, and relatively painless.

The two most common treatments for warts are patientapplied salicylic acid and physician- administered cryotherapy with liquid nitrogen [14]. However, other treatment have been proposed (Table 3 ). 
Table 2. Types of Viral Warts

\begin{tabular}{|l|}
\hline Common Warts \\
\hline $\begin{array}{l}\text { Common warts begin as smooth flesh coloured papules that enlarge and } \\
\text { develop a characteristic hyperkeratotic surface of grossly thickened } \\
\text { keratin. They can occur at sites of injury (Koebner phenomenon) }\end{array}$ \\
\hline Plantar Warts \\
\hline $\begin{array}{l}\text { Plantar warts occur on the soles of the feet and can be painful. They } \\
\text { protrude only slightly from the surface of the skin and often have a } \\
\text { surrounding collar of keratin }\end{array}$ \\
\hline Mosaic Warts \\
\hline $\begin{array}{l}\text { Mosaic warts occur as collections of small, discrete and densely packed } \\
\text { individual warts. They are often resistant to treatment }\end{array}$ \\
\hline Plane Warts \\
\hline $\begin{array}{l}\text { Superficial warts are flat topped papules, typically scattered over the face, } \\
\text { arms, and legs }\end{array}$ \\
\hline
\end{tabular}

Topical salicylic acid: The Cochrane review [14] identifies topical therapy with salicylic acid as safe and effective and reports that no clear evidence exists to prove that other therapies have an advantage in regard to higher cure rates or fewer adverse effects. Data pooled from six randomized trials gave a cure rate of $75 \%$ in cases compared with $48 \%$ in controls (odds ratio 3.91, 95\% confidence interval 2.40 to 6.36 ) [14]. Preparations containing salicylic acid include creams, ointments, paints, gels, and colloids, with concentrations of the active ingredient varying from $11 \%$ to $50 \%$. Over-the-counter preparations are less than 17 percent salicylic acid, whereas physician-prescribed preparations can contain as much as 70 percent salicylic acid [15]. Salicylic acid breaks down hyperkeratotic skin but does irritate children's skin. Topical salicylic acid should be regarded as first line treatment. The therapeutic benefit of topical therapies containing salicylic acid, whether over-thecounter or prescription, is supported by evidence from randomized controlled trials $[14,16,17]$.

Cryotherapy: Cryotherapy with liquid nitrogen, applied with a cotton-tipped swab (or cryogun) to freeze visible warts along with halo of surrounding tissue is a common and effective treatment for most warts. Application of the cryogen induces skin and vascular damage, leading to both epidermal and dermal cellular necrosis. Usually, two freeze/thaw cycles are undertaken, but the optimal number of applications has not been established. Cryogenic agents are relatively inexpensive and easy to apply, usually require no anesthesia, and cause little scarring after re-epithelialization. The treatment does not have systemic or distant cutaneous side effects. Pigmentary changes are not uncommon but are usually short term. Systematic reviews show that cryotherapy is no better than topical salicylic acid. Cryotherapy is best avoided in young children, as parents consider the side effects of pain, swelling, and blistering excessive for a benign self limiting condition. Aggressive cryotherapy scars children's skin. Cure rates for cryotherapy vary widely, depending on the treatment regimen. In general, the wart is frozen for 10 to 30 seconds until a 1 - to $2-\mathrm{mm}$ ice ball halo surrounds the targeted area. The highest cure rates are achieved when treatment occurs at a frequency of every two to three weeks $[16,18]$. However, the Cochrane review [14] reports that cryotherapy is no more effective than simple topical treatments for non genital cutaneous warts.

\section{Other Treatment}

Imiquimod (Aldara) is a topical immune response modifier manufactured as a 5 percent cream. Although randomized controlled trials are lacking, imiquimod has demonstrated potential efficacy in the treatment of recalcitrant non genital warts [19]. A review [20] however, found insufficient evidence to support the use of imiquimod for treatment of cutaneous nongenital warts.

Table 3. $\quad$ A = Consistent, Good-Quality Patient-Oriented Evidence; B = Inconsistent or Limited-Quality Patient-Oriented Evidence; $\mathbf{C}=$ Consensus, Disease-Oriented Evidence, Usual Practice, Expert Opinion, or Case Series

\begin{tabular}{|c|c|c|}
\hline \multicolumn{3}{|c|}{ Key Recommendations for Practice } \\
\hline Clinical recommendation & $\begin{array}{l}\text { Evidence } \\
\text { Rating }\end{array}$ & References \\
\hline $\begin{array}{l}\text { Topical salicylic acid therapy is recommended for } \\
\text { nongenitalcutaneous warts. }\end{array}$ & A & $\begin{array}{l}\text { Sterling JC, Handfield-Jones S, Hudson PM. Guidelines for the } \\
\text { management of cutaneous warts. Br J Dermatol 2001; 144: 4-11. } \\
\text { Gibbs S, Harvey I, Sterling JC, Stark R. Local treatments for cutaneous } \\
\text { warts. Cochrane Database Syst Rev 2004; (4): CD001781. }\end{array}$ \\
\hline $\begin{array}{l}\text { Cryotherapy is not recommended over salicylic acid for treatment } \\
\text { of nongenital cutaneous warts }\end{array}$ & A & $\begin{array}{l}\text { Brodell RT, Johnson SM. Warts: diagnosis and management: an evidence } \\
\text { based approach. New York: Martin Dunitz, } 2003 \text {. }\end{array}$ \\
\hline $\begin{array}{l}\text { There is poor evidence to recommend pulsed dye laser therapy for } \\
\text { nongenital cutaneous warts }\end{array}$ & B & $\begin{array}{l}\text { Gibbs S, Harvey I, Sterling JC, Stark R. Local treatments for cutaneous } \\
\text { warts. Cochrane Database Syst Rev 2004;(4):CD001781. }\end{array}$ \\
\hline $\begin{array}{l}\text { There is insufficient evidence to recommend imiquimod (Aldara) } \\
\text { for treatment of cutaneous warts. } \\
\text { There is inconsistent evidence to recommend bleomycin } \\
\text { (Blenoxane) for treatment of cutaneous warts. }\end{array}$ & B & $\begin{array}{l}\text { Sterling JC, Handfield-Jones S, Hudson PM. Guidelines for the } \\
\text { management of cutaneous warts. Br J Dermatol 2001; 144: 4-11. }\end{array}$ \\
\hline $\begin{array}{l}\text { Intralesional immunotherapy with Candida skin test antigen can } \\
\text { be used as a second-line therapy for cutaneous warts. }\end{array}$ & B & $\begin{array}{l}\text { Sterling JC, Handfield-Jones S, Hudson PM. Guidelines for the } \\
\text { management of cutaneous warts. Br J Dermatol 2001; 144: 4-11. } \\
\text { Brodell RT, Johnson SM. Warts: diagnosis and management: an evidence } \\
\text { based approach. New York: Martin Dunitz, } 2003 \text {. }\end{array}$ \\
\hline
\end{tabular}


Bleomycin (Blenoxane), a chemotherapeutic agent, inhibits DNA synthesis in cells and viruses. Bleomycin is an alternative therapy for warts that have not responded to other therapies or warts that may be difficult to surgically excise. Pain is the major limiting factor to treatment. Potential side effects include scarring, change in pigmentation, nail damage, and Raynaud's phenomenon [21]. The Cochrane review [14] states that there is no consistent evidence for the effectiveness of intralesional bleomycin for treatment of nongenital cutaneous warts, and the data could not be meaningfully pooled for analysis. Another review [15] based on four randomized controlled trials and multiple case series that provide evidence of the effectiveness of bleomycin, recommends its use as a third-line therapy for common and plantar warts.

Retinoids: Systemic retinoids have been used to treat warts because of their ability to alter keratinization and accelerate the clearing of warts by inducing an irritant dermatitis [22]. A small study [23] examined the efficacy of etretinate in children with extensive warts. Of the 20 children involved in the study, 16 demonstrated complete clearance of their warts without relapse. Warts recurred in four patients following partial regression.

Pulsed dye laser: Treatment with a vascular lesion laser, also known as pulsed dye laser therapy, can selectively target hemoglobin contained in blood vessels within the wart [24]. As the hemoglobin heats up, thermal energy is dissipated to surrounding tissues, leading to cauterization of blood vessels. The result is a necrotic wart that eventually sloughs off. Pulsed dye laser therapy is recommended as second-line therapy for plantar warts and third-line therapy for common warts and flat warts [15]. However, another review [20] found poor evidence to support the use of a single pulsed dye laser treatment because of problems with study methodology and listed it for the treatment of warts located on the hands and feet only.

Intralesional immunotherapy: Intralesional immunotherapy employs the ability of the immune system to recognize certain viral and fungal antigens. Candida skin test antigen generally is used. It is believed that the delayed-type hypersensitivity reaction induced by these antigens increases the ability of the immune system to recognize and clear HPV. Although the number of published randomized clinical trials remains limited, one review [15] recommended intralesional immunotherapy as second-line therapy for plantar warts and third-line therapy for common and flat warts.

Photodynamic therapy: Fabbrocini et al. [25] investigated the effect of photodynamic therapy (PDT) with topical delta-aminolaevulinic acid (ALA) on plantar warts. This study shows that topical ALA-PDT can be an alternative treatment for plantar warts, in agreement with Stender and co-workers [26] who successfully treated recalcitrant hand and foot warts with ALA-PDT.

\section{ANO-GENITAL WARTS}

HPV infections of genitalia have increased considerably and they are now the leading sexually transmitted diseases. [27]. Partly reflecting the increased prevalence in the adult population and a greater awareness of this disease, anogenital warts in pediatric patients are also on the rise as indicated by the reports of at least 21 cases by 1980 [28], 136 cases prior to 1990 , as compared to 339 additional cases between 1990 and 1995 [29]. Ano-genital warts manifest either as small papules (small, smooth, and dome shaped) or as large acuminate papules and plaques (Fig. 3).

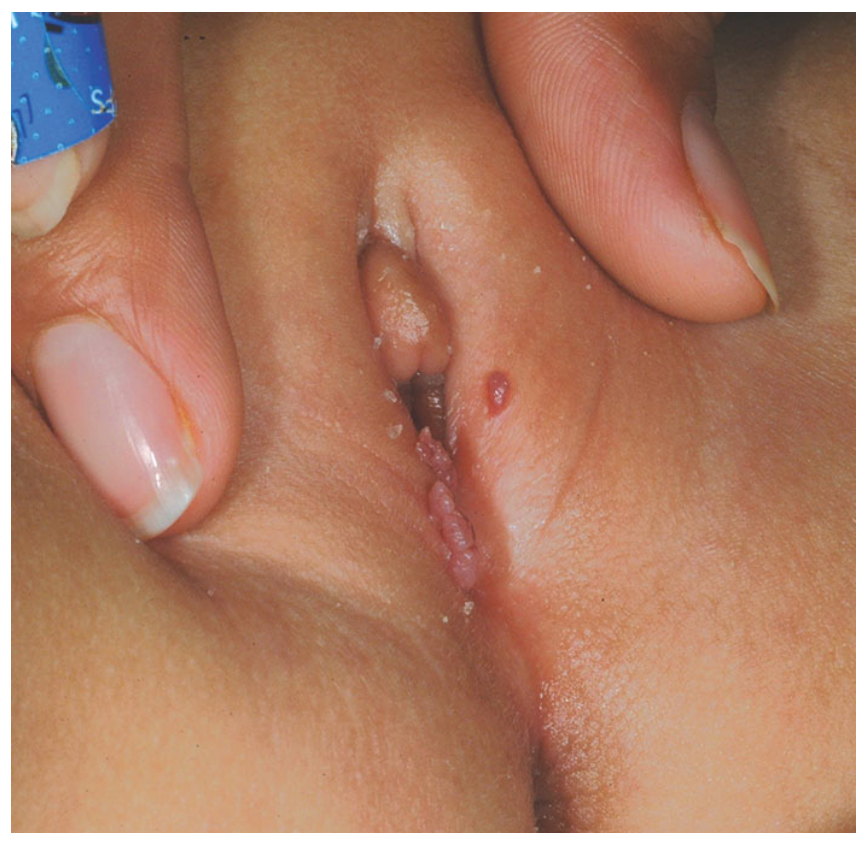

Fig. (3). HPV genital warts of a 2-year-old girl.

HPV genital infection is difficult to treat because the virus produces small amounts of HPV antigen (located in relatively inaccessible areas of the epidermis) that can elude the immune system. In addition, after destructive treatments HPV DNA continues to reside in the margins outside of the treatment area [30]. The proper approach to the management of warts depends on the age of the patient, location, size, extent, and type of wart, and duration of lesions. The patient's immunologic status, cooperation and tolerance of adverse reactions are also important factors that influence results. The ideal therapy should be effective (i.e. high clearance and low recurrence rates) and cause minimal local and systemic adverse effects. Several treatment options are available for condyloma in adults; none have been studied or approved by the US Food and Drug Administration for treatment of children. Current therapies such as topical acids, cryotherapy, laser vaporization, electrocautery, surgical excision, and topical cytotoxic agents are designed to destroy infected epithelial cells $[31,32]$. Suggested investigations and management of HPV infection in children include: a paediatric assessment; behavioural indicators; tests for other STD in the child and careers; typing of warts is expensive and may be misleading as non-genital wart types may be sexually transmitted - for example; digital and genital wart types transmitted in uterus; a social worker with or without police investigation; follow up appointments for adolescents are recommended; joint clinics with genitourinary physicians are ideal; follow up of prepubescent children is more difficult and currently we refer back to the general practitioner for assessment, possibly at the first family planning clinic; locally, treatment of AGW is surgical. Early recognition of ano-genital warts as a marker for child sexual abuse may allow early cessation of the abuse, giving the child an improved chance of developing into a mature adult 
with the ability to form lasting relationships. Undoubtedly, the assessment of pediatric ano-genital warts as a result of possible sexual abuse is one of the most difficult issues in the entire field of HPV epidemiology.

\section{Human Papillomavirus Vaccine for Children}

In 2006, the first vaccine for the prevention HPV infection was approved for use in Canada in females nine to 26 years of age. Since that time, several issues of potential controversy have been identified in both the medical literature and public media. These largely question the appropriateness of prioritizing public funds for this vaccine over other potential public health interventions, the longterm safety and efficacy of the vaccine, and the role of the pharmaceutical industry in communicating directly to the public regarding the vaccine. The vaccine is manufactured using recombinant technology resulting in noninfectious virus-like particles containing protein antigens for each genotype. It targets the two high-risk oncogenic HPV genotypes responsible for the majority of cervical cancers, as well as two low-risk genotypes that are associated with over $90 \%$ of genital warts. The aim of the vaccine is to prevent infections and, thus, the diseases subsequently associated with HPV-6, -11, -16 and -18. It is not a therapeutic vaccine and, therefore, must be given before the acquisition of infection with the virus to be optimally effective. A recent study [33] has demonstrated long-term HPV type-specific immune memory with excellent boosting of antibodies following a fourth dose of HPV vaccine five years after the initial series. The vaccine has been shown to induce a robust immunological response to the component genotypes with greater than $99.5 \%$ mounting antibody levels at or above those induced by natural infection, one month after completing the vaccine series. Postvaccination, neutralizing antibodies have also been demonstrated in cervical secretions. Antibody titers across all vaccine genotypes were significantly higher in adolescent boys and girls (nine to 15 years of age) than in adults $[34,35]$. The quadrivalent HPV vaccine is safe and well tolerated. However, as with all new vaccines, it is important to conduct postmarketing surveillance to identify any unexpected, rare adverse events that may arise.

\section{REFERENCES}

[1] Clifford G, Franceschi S, Diaz M, Muñoz N, Villa LL. HPV typedistribution in women with and without cervical neoplastic diseases. Vaccine 2006; 24(Suppl): 26-34.

[2] Mammas IN, Sourvinos G, Spandidos DA. Human papilloma virus (HPV) infection in children and adolescents. Eur J Pediatr 2009; 168: 267-73.

[3] Gutman LT, St Claire KK, Weedy C, Herman-Giddens M, McKinney RE Jr. Sexual abuse of human immunodeficiency viruspositive children. Outcomes for perpetrators and evaluation of other household children. Am J Dis Child 1992; 146: 1185-9.

[4] Moscicki AB, Palefsky J, Gonzales J. Human papillomavirus infection in sexually active adolescent females: prevalence and risk factors. Pediatr Res 1990; 28: 507-13.

[5] Fisher M, Rosenfeld WD, Burk RD. Cervicovaginal human papillomavirus infection in suburban adolescents and young adults. J Pediatr 1991; 119: 821-5.

[6] Schwarcz SK, Whittington WL. Sexual assault and sexually transmitted diseases: detection and management in adults and children. Rev Infect Dis 1990; 12: S682-9.
[7] Plasencia JM. Cutaneous warts: diagnosis and treatment. Prim Care 2000; 27: 423-34.

[8] Gibbs S, Harvey I, Sterling JC, Stark R. Local treatments for cutaneous warts. Cochrane Database Syst Rev 2003; 3: CD001781.

[9] Williams HC, Pottier A, Strachan D. The descriptive epidemiology of warts in British schoolchildren. Br J Dermatol 1993; 128: 50411.

[10] Massing AM, Epstein WL. Natural history of warts. A two-year study. Arch Dermatol 1963; 87: 306-10.

[11] Clifton MM, Johnson SM, Roberson PK, Kincannon J, Horn TD. Immunotherapy for recalcitrant warts in children using intralesional mumps or Candida antigens. Pediatr Dermatol 2003; 20: 268-71.

[12] Sterling JC, Handfield-Jones S, Hudson PM. Guidelines for the management of cutaneous warts. Br J Dermatol 2001; 144: 4-11

[13] Berth-Jones J, Hutchinson PE. Modern treatment of warts: cure rates at 3 and 6 months. Br J Dermatol 1992; 127: 262-5.

[14] Gibbs S, Harvey I, Sterling JC, Stark R. Local treatments for cutaneous warts. Cochrane Database Syst Rev 2004; (4): CD001781.

[15] Brodell RT, Johnson SM. Warts: diagnosis and management: an evidence based approach. New York: Martin Dunitz 2003.

[16] Bunney MH, Nolan MW, Williams DA. An assessment of methods of treating viral warts by comparative treatment trials based on a standard design. Br J Dermatol 1976; 94: 667-79.

[17] Bart BJ, Biglow J, Vance JC, Neveaux JL. Salicylic acid in karaya gum patch as a treatment for verruca vulgaris. J Am Acad Dermatol 1989; 20: 74-6.

[18] Bourke JF, Berth-Jones J, Hutchinson PE. Cryotherapy of common viral warts at intervals of 1, 2, and 3 weeks. Br J Dermatol 1995; 132: 433-6.

[19] Grussendorf-Conen EI, Jacobs S. Efficacy of imiquimod 5\% cream in the treatment of recalcitrant warts in children. Pediatr Dermatol 2002; 19: 263-6.

[20] Sterling JC, Handfield-Jones S, Hudson PM. Guidelines for the management of cutaneous warts. Br J Dermatol 2001; 144: 4-11.

[21] Vanhooteghem O, Richert B, de la Brassinne M. Raynaud phenomenon after treatment of verruca vulgaris of the sole with intralesional injection of bleomycin. Pediatr Dermatol 2001; 18: 249-51.

[22] Aboosi M. Treatment of plane warts by tretinoin-induced irritant reaction. Int J Dermatol 1994; 33: 826-7.

[23] Gelmetti C, Cerri D, Schiuma AA, Menni S. Treatment of extensive warts with etretinate: a clinical trial in 20 children. Pediatr Dermatol 1987; 4: 254-8.

[24] Hruza GJ. Laser treatment of epidermal and dermal lesions. Dermatol Clin 2002; 20: 147-64.

[25] Fabbrocini G, Di Costanzo MP, Riccardo AM, et al. Photodynamic therapy with topical delta-aminolaevulinic acid for the treatment of plantar warts. J Photochem Photobiol B 2001; 61: 30-4.

[26] Stender IM, Na R, Fogh H, Gluud C, Wulf HC. Photodynamic therapy with 5-aminolaevulinic acid or placebo for recalcitrant foot and hand warts: randomised double-blind trial. Lancet 2000; 355: 963-6.

[27] Fenton KA, Korovessis C, Johnson AM, et al. Sexual behaviour in Britain: reported sexually transmitted infections and prevalent genital Chlamydia trachomatis infection. Lancet 2001; 358: 1851-4.

[28] Boyd AS. Condylomata acuminata in the pediatric population. Am J Dis Child 1990; 144: 817-24.

[29] Syrjänen S, Puranen M. Human papillomavirus infections in children: the potential role of maternal transmission. Crit Rev Oral Biol Med 2000; 11: 259-74.

[30] Coleman N, Birley HD, Renton AM, et al. Immunological events in regressing genital warts. Am J Clin Pathol 1994; 102: 768-74.

[31] Moscicki AB. Genital HPV infection in children and adolescents. Obstet Gynecol Clin N Am 1996; 23: 675-97.

[32] Armstrong DK, Handley JM. Anogenital warts in prepu- bertal children: pathogenesis, HPV typing and manage-ment. Int J STD AIDS 1997; 878-81.

[33] Olsson SE, Villa LL, Costa RL, et al. Induction of immune memory following administration of a prophylactic quadrivalent human papillomavirus (HPV) types 6/11/16/18 L1 virus-like particle (VLP) vaccine. Vaccine 2007; 25: 4931-9. 
[34] Reisinger KS, Block SL, Lazcano-Ponce E, et al. Safety and Persistent immunogenicity of a quadrivalent human papillomavirus types $6,11,16,18 \mathrm{~L} 1$ virus-like particle vaccine in preadolescents and adolescents: A randomized controlled trial. Pediatr Infect Dis J 2007; $26: 201-9$
[35]

Block SL, Nolan T, Sattler C, et al. Comparison of the immunogenicity and reactogenicity of a prophylactic quadrivalent human papillomavirus (types 6,11, 16, and 18) L1 virus-like particle vaccine in male and female adolescents and young adult women. Pediatrics 2006; 118: 2135-45.

(C) Fabbrocini et al.; Licensee Bentham Open.

This is an open access article licensed under the terms of the Creative Commons Attribution Non-Commercial License (http://creativecommons.org/licenses/by$\mathrm{nc} / 3.0 /$ ) which permits unrestricted, non-commercial use, distribution and reproduction in any medium, provided the work is properly cited. 